\title{
Cultivating the College Students’ Creative Thinking in Industrial Design
}

\author{
Hua Cen ${ }^{1}$, Chuandong $\mathrm{Ma}^{2 *}$ \\ ${ }^{1}$ The Engineering College of Sichuan Normal University, Chengdu, China \\ ${ }^{2}$ The Fundamental College of Sichuan Normal University, Chengdu, China \\ Email: *machaundong2006@163.com
}

Received June $5^{\text {th }}$, 2013; revised July $5^{\text {th }}$, 2013; accepted July $13^{\text {th }}, 2013$

\begin{abstract}
Copyright @ 2013 Hua Cen, Chuandong Ma. This is an open access article distributed under the Creative Commons Attribution License, which permits unrestricted use, distribution, and reproduction in any medium, provided the original work is properly cited.
\end{abstract}

\begin{abstract}
This paper probes into the source of "originality" in developing the creative thinking of the science students majoring in industrial design. The authors believe that the critical factors for the source of "originality" lie in not only the internal cause, but also the external cause. Whether the science students take a great consideration of art and humanity courses, in other words, whether they are aware of the relationship between artistical thought and industrial design or not, it is very important. In addition, creative capacity cannot be taught, and it only results from inspiration and guidance of teachers from multidisciplinary.
\end{abstract}

Keywords: Creative Thinking; Artistic Thought; Industrial Design; Multi-Disciplinary

\section{Introduction}

China (Mainland) Ministry of Education published and implemented "the Undergraduate Specialty Catalogue of Higher Institutions (New)" in 2012, in which it clearly stated that, the specialty: Industrial Design, remains in the enginery specialty included in Engineering, mainly enrolling science students, and arts students will be included in the newly-set Art Specialty: Product Design. Most of the science students who major in Industrial Design are excellent in logical deduction but poor in creative thinking needed for their specialty, therefore, it is urgent to rearrange courses for the science students in order to improve their creative thinking.

The Industrial Design Specialty and Product Design Specialty including in Engineering or Arts have developed for more or less twenty years in China, so their curriculum systems are much of a muchness. The core courses for both of them consist of three parts: basic modeling courses, design fundamental courses and specialty design courses, only with slight differences in the percentages of general education courses, specialized courses and practical courses.

The author is convinced that the reason why the science students are poor in originality and expression is not because of the differences in the percentage of the courses, but because of the internal cause and external cause listed as follow: First, as far as the students themselves are concerned, the science students pay little attention to the relationship between artistical thought and creative design of the industrial products, as a result they neglect the study of the basic modeling courses, which in fact is the most important way in cultivating the artistical thought of the science students; Second, as far as the teachers are concerned, the inspiration and guidance of the teachers are also of critical importance. Teachers should make the students

\footnotetext{
*Corresponding author.
}

aware of the fact that art and humanity courses underlie their specialty design courses. In addition, in the process of teaching, teachers should bring in interactive teaching model, introducing comprehensive contents from multi-disciplinary so that the students can get to know better the knowledge of each course. Only in this way can the teachers inspire the creative thinking of the students.

\section{The Relationship between Artistical Thought and Creative Design of Industrial Products}

If we want to make the science students interested in art courses and help them realize their importance and the relationship between artistical thought and creative design of industrial products, we should first of all make clear the field and ultimate goal they focus on. Art is unconstrained and un-normalized, and it aims to express self aspiration through certain art forms, such as, graphic art, stereoscopic art or behavior. On the contrary, industrial design aims to solve the problem between human, machine and environment, so industrial design is rational, constrained and normalized, a process of the application of the intersection of multi-disciplinary. Artistical thought provides to creative industrial design rich thinking and broad space, while creative industrial design brings to artistical thought sophisticated means in art innovation. We can represent their relationship as follow (see Figure 1).

Thinking includes logical thinking and illogical thinking, just like the "engine" of originality with different functions. Logical thinking is a process of induction, deduction, analysis, abstraction and integration, while illogical thinking is the thinking forms of instinct, inspiration, imagination and association. Imaginal thinking originates from illogical thinking so as to form clues for innovation. When crisscross clues rush into our mind, we explore the relation among the clues by using our logical 


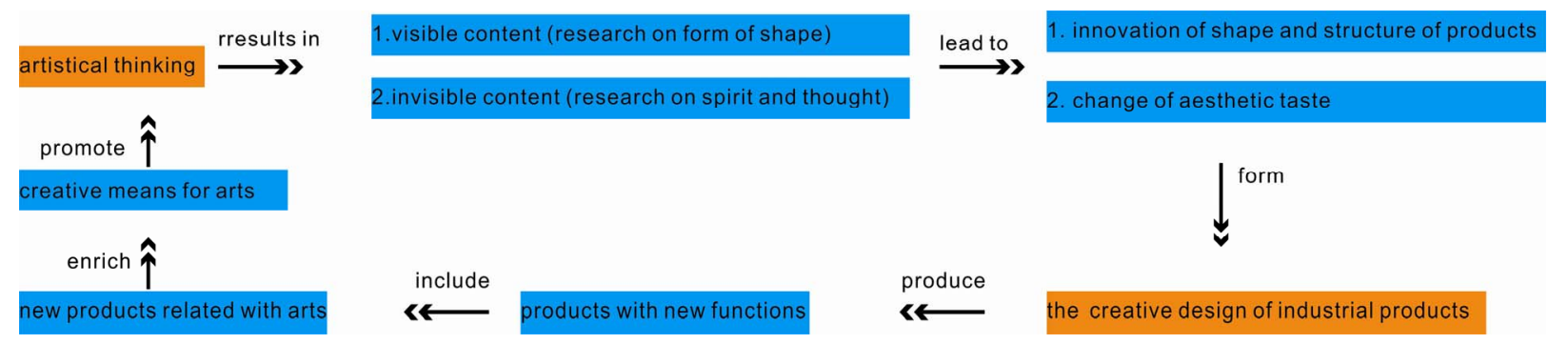

Figure 1.

The relationship between artistical thinking and the creative design.

thinking in order to find out the regularity, induct or deduct the target creative point (Chang Shubing \& He Anhua, 2006). For example, before we position our product design, too much information gathered from the market research confuse us and we do not know how to deal with it. Then, only when we have a clear thinking can we induce the information, improve our analysis, find out the problems, make clear the primary and secondary relation of the problems, and finally make a correct judgment and hit the target design. After positioning the design, we should set to solve the following problem: how to meet the need of everybody with the means others have never thought of. This is what the creative thinking or imaginal thinking aims to do. Thus it is self-evident that logical thinking and illogical think play different roles in design, which proves the complementarity of art and science in industrial design.

Art aims at aesthetic appreciation and art expresses one's spiritual feeling. The creation of art image comes from imaginal thinking, that is, illogical thinking. Imaginal thinking is a unity of intuition, imagination and emotion. Einstein once said, "I believe in intuition and inspiration... Imagination is more important than knowledge, because knowledge is limited, but imagination summarizes everything in the world, driving the progress, and is the source of knowledge evolution. Strictly speaking, the imagination is a real factor in scientific research.” (Xu Liangying \& Fan Dainian, 1976). It is one of the most important ways for us to develop the students' sensitivity in imaginal thinking and improve their ability in industrial design innovation. Industrial design is a multi-disciplinary based on science, technology and humanistic spirit, including innovation in function and modeling. It reflects the unity of function and modeling. The function of a product contains two aspects: spiritual and functional, and both of them are embodied in its modeling. The innovation of aesthetic modeling is realized through our imaginal thinking. For example, in courses for sketch and color, we are trained in our visual observation and expression. When observing people, scenery and substance in the process of painting, we should turn from one angle to another so as to get a deeper understanding of the object, and grasp the nature of it. Everything exists in the universe as a system, like an organic integrity consisting of multi-perspective and multi-leveled factors relating with each other, depending on each other and restricting each other. Innovators thus need to ponder things in the system, taking all the analysis and synthesis on multi-perspective and multi-levels into consideration, so as to find out the inner links related. Innovators cannot observe a thing in isolation with one certain way of thinking, but they need to use various ways of thinking to make the modeling factors united and changeable. Only in this way can the innovators express the human factors (cultural, psychological, phy- siological) through forms from the social aspect. In the traditional art constitution course, thought training in the spatial distribution of point, line and plane is the core means in product modeling innovation. For example, when we are creating the model of a product, we do addition or substraction to get the shape by means of segmentation in the three-dimentional composition and accumulation of basic forms. This shape should not only embody our design philosophy, but also follow the universal law for beauty, that is, beauty in harmony. In creating inner beauty in harmony, we can make use of the techniques in constitution course, such as the repeated combination of the identical unit shapes, or constitution of ordered space with different shapes. The color expression, the coordination for the proportional relation and material selection for different products reflect the quality of the designer in the aesthetic taste and sensitivity in market observation, and the improvement of this kind of quality usually depends on the imaginal thinking. For example, from the improvement of cellphone showed in the following pictures (see Figure 2), we can clearly see the better visualization of the product with the development of the society and the change of the aesthetic idea. That is the materialization of imaginal thinking in the industrial design.

In the process of designing, what we need is not only the good design philosophy, but also effective ways of expression, by means of hand-made drawing or computer aided design, which is in itself a process of thinking innovation. We should inherit the present painting skills, and at the same time, take the characteristics of the time into consideration so as to create more fresh and alive ways of expression. Why not blend the expression skills used in cartoon, or the traditional paper cut arts, or the performance techniques used by Clay Figurine Zhang in the product expression to blaze a trail for that in product design? Thoughts on these display the art re-creation. People have a common sense on beauty, thus it is universal in the innovation for product design for the aesthetic principle, way of thinking and pattern of manifestation researched on in the imaginal thinking.

Creative thinking is more complicated in exploring things unknown, and it is the dialectical unity of divergent thinking and convergent thinking. It is a dynamic integration of creative imagination and reality orientation, and a unity of opposites of abstract thinking and convergent thinking. Creative thinking, initiative and original, can reveal the law and nature of objective reality and bring about novel, unique fruits of social meanings, through which we can open up a new field for human knowledge.

The differences of the ultimate goal between imaginal thinking and industrial design innovation lead to their diversities. First, design itself is a creative activity when human beings 


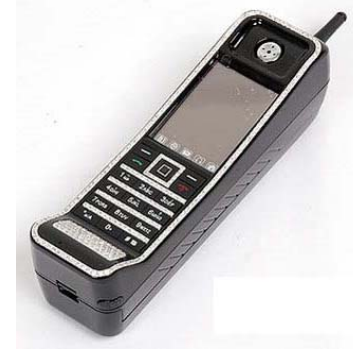

(a)

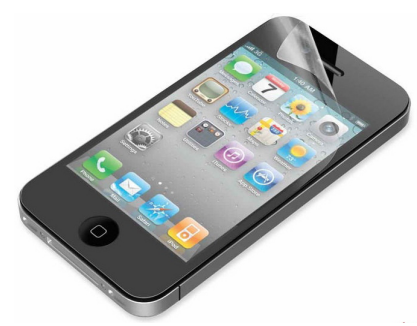

(b)
Figure 2.

(a) Cellphone in early; (b) Iphone at present.

conceive to remake the nature and society. Industrial designers aim at making clear the relation between people, machine, and environment so as to make the product meet the people's need for material and for spirit as well. Therefore, product innovation requires the perfect combination of techniques and arts, guided by the market, surpassing the trend and providing healthy living ways for people of today and tomorrow ( $\mathrm{Li}$ Yanzu, 2005). We can say that the innovative thinking for products is both objective and subjective. Second, when we come to product innovation, we must find out the main factors which effect product innovation in order to distinguish it from imaginal thinking. The starting-point of product innovation is to find the potential need of human beings, in another word, it is people oriented, while imaginal thinking is only one means to realize the innovation. Industrial design thoughts are practicalminded, seeking for the need of the society and the disparity between people's ideal and reality. We should broaden our thoughts to meet the needs of the society, because there are various needs, some obvious and some recessive. The obvious needs are easy to see and we can try to find way to meet the needs that everybody thinks of through innovation thinking, while the recessive needs cannot be uncovered without creative discovery. Imaginal thinking can aids product designers to become not only the explorers of developing science and technology, but and at the same time, the labor force for the application of the new technology. The development product design is a course set for the students majoring in industrial design, which aims at making use of new technology to provide support for developing new products.

Only dreams can push us to a new starting point. The Wright brothers set us a very good example, who succeeded in applying the research findings in aero-dynamics and realized the dreams of human beings, flying to the sky one hundred years ago. Figure 3 shows the first plane made by the Wright brothers. And the dream also blazed a trail for the development of aerotechnics.

Intelligence comes next. It is generally agreed that those who are mentally handicapped may become a great artist, but this is not true for an industrial designer. Design is to solve problems, requiring one's capability in logical judgment and needed knowledge. Just as the logical thinking mentioned above, it is one of the embodiment of design capability, requiring one's ability in induction, deduction, analysis, abstraction and synthesis. Imaginal thinking allows one person to express his own idea and display his personality, but product innovation serves for the broad masses of people, it is a creative activity for the whole society.

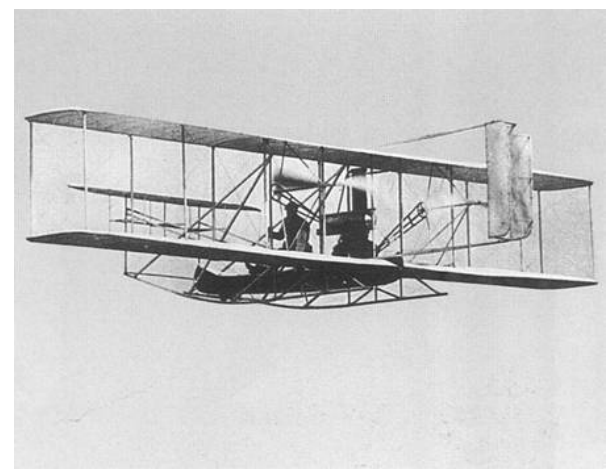

Figure 3.

The first plane made by the Wright brothers.

\section{Suggestions on the Curriculum and Teaching Model for Students of Industrial Design}

We, as the educators or designers of industrial design, should keep pace with the time in the ways of thinking and combine technology with humane spirit, because our worldview and values directly decide our creative thinking and the social and economic benefits of the product. In a word, artistical thinking centers on imaginal thinking, while industrial design innovation depends on logical thinking aided by imaginal thinking ( $\mathrm{Li}$ Yanzu, 2005).

The basic courses for industrial design include humanistic quality education and professional quality education. At present, teaching and evaluation criterion for majors in design in colleges in China (Mainland) are simple and one-dimentional. Students are only offered several integrated courses and art courses, and administrators neglect the continuity, relevance and enlightenment of each course, which is surely not in accordance with the characteristics of industrial design, the combination of technology and art. The authors suggest that courses for humanistic quality education should be arranged together with the design courses. For example, when we are teaching students the tourism product design, administrators for industrial design department should invite those teaching history, business or literatures to give lectures to the science students majoring in industrial design to enrich their knowledge and broaden their view. This can not only help them to learn a lot from the history, but also inspire the students' creative thinking to explore the potential market for tourism products so as to make serial products typical of Chinese culture. They can design series of products typical of Chinese culture, as shown in the following two products designed by the students: (Figures 4 and 5).

This product “檐伞” (Yan umbrella in English) is the improved version of the Chinese traditional oil papered umbrella. “檐” has the same pronunciation with “延” yan, which means prolong life, and “檐” also means family or home. The improved version made the oil papered umbrella smaller and much easier to carry, really representing the developmental heritage of Chinese culture.

“影砚” is a tourism product called inkstone, which is designed according to the local architectural feature and the inkstone, a cultural symbol in China, representing the traditional architectural feature of Hong Cun (a small village in Anhui Province in China). Chinese ink reflects the white wall and black tiles, forming a delightful contrast for the calligraphers. 


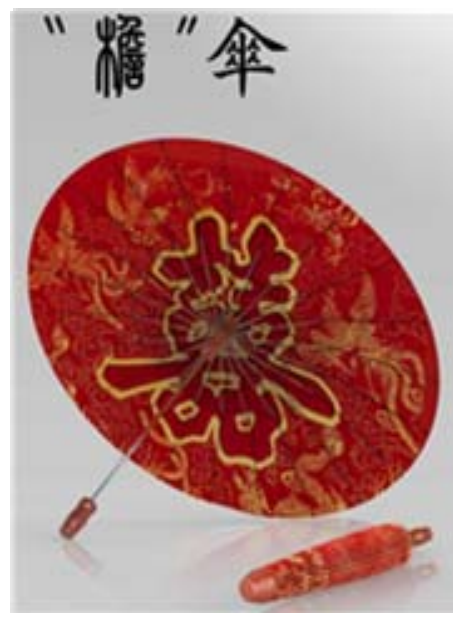

Figure 4.

"Yan” Umbrella (Designer: Liu Yinjie, Luo Yunhao).

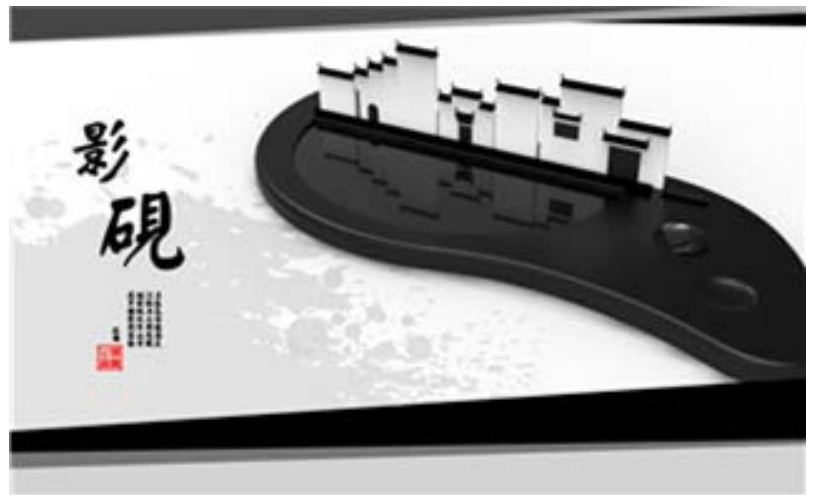

Figure 5.

Ying Inkstone (Designer: Song Shuning).
When teachers introduce such courses as transportation tools or product development and design, they can invite teachers in biological science or geographic or resources science. The research field of biological science can lead the students to view the development of human being and nature in the future. The structures of living things can draw the students' attention to the innovation of product structure and function. The knowledge system of geography and resources science can also trigger students' interest in ecological design. The exploration of the interactive teaching of multi-disciplinary can not only make the teaching of speciality courses reach a perfect combination of technology and art, but also effectively develop the students' creative thinking, a kind of all-direction divergent thinking.

\section{Conclusion}

The construction of the innovative thinking courses for industrial design depends not on the courses for design thinking, design principles or design psychology, but on the embodiment of the dialectic relation of internal cause, or in other words, the students subjective cognizance on the humane and art courses, and the external cause, that is, the proper guidance of the teachers. Creative capability cannot be taught, and it can only be gained in the process of inspiration and proper guidance of the teachers. If science and technology is the means for innovation, then humane spirit provides it direction of development, the most important source for innovation.

\section{REFERENCES}

Chang, S. B., \& He, A. H. (2006). Creation originates from illogical thinking. Frontier, 4.

Li, L. S. (2005). Industrial design psychology. Beijing: Higher Education Press.

Li, Y. Z. (2005). Arts and science. Beijing: Tsinghua University Press. Xu, L. Y., \& Fan, D. N. (1976). Einstein's collections. Beijing: The Commercial Press. 